\title{
Editorial
}

\section{Subjetividade, verdade e poder: contribuições da obra "A Arqueologia do Saber" para os estudos da linguagem}

\author{
Pedro NAVARRO \\ Universidade Estadual de Maringá (UEM/CNPq) \\ https://orcid.org/0000-0003-3267-4985
}

Ivânia dos Santos Neves

Universidade Federal do Pará (UFPA/CNPq)

http://orcid.org/0000-0002-6738-5254

Os artigos deste dossiê, conjuntamente com os que compõem o primeiro volume, seguem a tarefa de mobilizar e de problematizar conceitos e noções desenvolvidos por Michel Foucault, em sua "A Arqueologia do Saber”, cuja publicação completou 50 anos, em 2019. Nestes dois volumes, com muito prazer, além de autores já reconhecidos em nossa área, reunimos significativos artigos de jovens pesquisadores da Amazônia e do Nordeste, que nos permitem compreender a dimensão nacional dos Estudos Discursivos foucaultianos e traduzem o esforço empreendido nas últimas duas décadas em ampliar a pós-graduação em nosso país. Apesar dos retrocessos do momento atual, a pesquisa resiste, desponta e aponta para um futuro promissor.

Os autores e as autoras dos artigos concentraram-se na tarefa de apresentar possibilidades de análise de fatos de discurso voltadas ao exercício do poder e à produção de verdades que fabricam sujeitos, objetos e saberes, ao mesmo tempo em que podem suscitar movimentos de resistência, mais ou menos visíveis, silenciosos ou mais barulhentos em nossa sociedade contemporânea. Alguns trabalhos estão mais voltados para questões que configuram um método de análise de discursos que pode ser depreendido das regras de formação discursiva, outros assentam-se em tal aporte para compreender a espessura material do poder.

Apesar de os artigos não responderem a Foucault se é "É inútil revoltar-se?"1, há um empenho considerável para adentrar as condições históricas em que se dá o exercício do poder, compreender até onde e como ele se exerce em um campo de lutas e de batalhas. É nesse sentido que se é imprescindível o retorno às formulações foucaultianas que podemos encontrar na fase arqueológica de constituição do saber, justamente porque lá está o direcionamento para pôr em batimento a ideia de discurso como "conjunto regular de fatos linguísticos em determinado nível, e polêmicos e estratégicos em outro"2. Nessa direção, é possível dar algumas respostas à indagação de Foucault, porém elas resultam da observação e da investigação de como o discurso vai se configurando, no e pelo sistema de enunciabilidade que os artigos reorganizam, e isso passa, necessariamente, pela teoria do enunciado.

Várias são as entradas no corpus discursivo que conduzem os pesquisadores a essa prática de análise. Uma delas se dá pelo tema da raridade enunciativa, que leva em conta aquilo que Foucault ${ }^{3}$ avalia em termos de

\footnotetext{
${ }^{1}$ FOUCAULT, Michel. É inútil revoltar-se? In: MOTTA, Manuel Barros da (org.). Ditos e escritos V: Ética, Sexualidade, Política. Tradução de Elisa Monteiro; Inês Autran Dourado Barbosa. Rio de Janeiro: Forense Universitária, 2004, p. 77-81.

${ }^{2}$ FOUCAULT, Michel. A verdade e as formas jurídicas. Tradução de Roberto Cabral de Melo e Eduardo Jardim Morais. Rio de Janeiro: NAU Editora, 2002, p.9.

${ }^{3}$ FOUCAULT, Michel. A arqueologia do saber. Tradução de Luiz Felipe Baeta Neves. Petrópolis: Vozes; Lisboa: Centro do Livro Brasileiro, 1972.
} 
"valor" dos enunciados, a saber o lugar que ocupam em dada repartição discursiva, incluindo a sua capacidade de circulação, de troca e de transformação na economia dos discursos. Considerando-se o fato de que poucas coisas são ditas, as análises deflagram a multiplicação dos sentidos vinculados aos enunciados, e esse é o direcionamento dado pela concepção de discurso com a qual trabalhamos no campo dos Estudos Discursivos foucaultianos. É o texto de “A Arqueologia do Saber" que sustenta essa prática: “Assim concebido, o discurso [...] aparece como um bem - finito, limitado, desejável, útil - que tem suas regras de aparecimento e também suas condições de apropriação e de utilização; um bem que coloca, por conseguinte, desde sua existência (e não simplesmente em suas 'aplicações práticas'), a questão do poder; um bem que é, por natureza, o objeto de uma luta, e de uma luta política"4 . Essa citação orienta, pois, nosso olhar para a investigação de como o poder atua por meio dos enunciados, em sua condição de raridade. Não obstante poucas coisas serem ditas, o poder que nelas se manifesta potencializa seus efeitos, e, para tanto, as instituições desempenham um papel significativo.

Outra possibilidade de entrada no arquivo disperso e heterogêneo organizado e sob investigação neste dossiê é pela noção de monumento, tão cara à perspectiva histórica que baliza nossa forma de abordagem da relação entre subjetividade, verdade e poder. Isso requer que acolhamos os discursos em sua condição de prática que obedece a regras que são determinadas pelas instituições e respondem pelos tipos de objeto, pelos conceitos, pelas modalidades de enunciação, pelas estratégias e pelas relações que se estabelecem entre os enunciados. Se fosse possível reunir essa prática de análise em uma única formulação, diríamos que monumentalizar os discursos é considerar que nenhum enunciado é inativo, visto que coloca em funcionamento regras de formação que são definidas pela ordem discursiva e pelo dispositivo de poder predominantes em dado momento histórico.

Aludimos, com isso, à ideia de que a verdade é uma invenção, portanto é deste mundo; contudo, para se chegar a essa constatação, devemos estar atentos às orientações que uma história-monumento fornece à análise de discursos: "o problema é constituir séries: definir para cada uma seus elementos, fixar-lhes os limites, descobrir o tipo de relações que lhe é específico, formular-lhes a lei e, além disso, descrever as relações entre as diferentes séries, para constituir, assim, séries de séries, ou "quadros" "5. Em outras palavras, a monumentalização dos documentos requer que trabalhemos com a noção de prática discursiva, com base na qual é possível identificar o feixe de relações que o discurso emprega para produzir os objetos de que fala, como é o caso da figura do delinquente, exposto em “A Arqueologia do Saber”, pelo exame que Foucault faz do discurso da Psicopatologia, do século XIX.

Regras de formação discursiva de um lado, estruturação e atravessamento de redes de poder, de outro, nossa linha de raciocínio nos conduz ao que se convencionou chamar de método arqueogenealógico, mobilizado nos artigos deste segundo dossiê e nos que compõem o primeiro volume: a necessária correlação entre a vontade de saber (verdade) e as relações de poder. Por essa razão, nosso ponto de partida é, insistimos, "A Arqueologia do Saber", com as ferramentas que nela estão dispostas para a descrição do encontro do discurso com a vontade de verdade e a instância do poder que os envolve.

\footnotetext{
${ }^{4}$ Ibid., p. 136-37.

${ }^{5}$ FOUCAULT, Michel. A arqueologia do saber. Tradução de Luiz Felipe Baeta Neves. Petrópolis: Vozes; Lisboa: Centro do Livro Brasileiro, 1972, p. 177, p. 8.
} 
A força do comentário ${ }^{6}$ exerce seu efeito de retorno, novamente, a essa obra de Foucault, na qual ele explica que a análise arqueológica se dirige aos discursos "para descrever [...] um campo institucional, um conjunto de acontecimentos, de práticas, de decisões políticas, um encadeamento de processos econômicos em que figuram oscilações demográficas, técnicas de assistência, necessidades de mão-de-obra, níveis diferentes de desemprego etc" "7. Nós, autores que assinamos os artigos de ambos os dossiês, realizamos análises arqueológicas que façam emergir as relações estabelecidas entre formações discursivas, instituições, acontecimentos políticos e culturais, práticas de governo e processos de subjetivação, guindo-nos pelas direções metodológicas que contemplam uma concepção de discurso como conjunto de enunciados, a tese de que a prática discursiva produz os elementos de certo domínio de saber e o trabalho incessante de monumentalização discursiva.

Reiteramos que o nosso objetivo, neste Editorial, é mostrar como a articulação entre saber, verdade e poder delineia uma grade de leitura para as reflexões a respeito do sujeito, que são feitas no dossiê, e como essa articulação permite observar, por meio da descrição de práticas discursivas, o funcionamento de certos dispositivos na produção de subjetividades. O poder é micro também, e deve ser visto como algo que produz domínios de objetos, rituais de verdade e corpos dóceis e controlados. Saberes como os da biomedicina, da engenharia genética e de outros campos científicos auxiliam na cura de doenças, por exemplo, e isso atesta a positividade do poder.

Se voltarmos ao texto de "A ordem do Discurso", já citado, encontraremos uma das formas de manifestação do dispositivo de poder, por intermédio de práticas discursivas que estabelecem divisões, por exemplo, entre verdadeiro e falso, razão e desrazão ou interdições, como as que definem o que é permitido ou não falar, quem pode falar e em que circunstâncias é possível que isso se efetive. Foucault considera que é nas regiões da sexualidade e da política que os mecanismos de interdição ganham mais força e mais visibilidade. Um pouco antes da publicação de sua aula no Collège de France, o autor adiantou a dinástica do poder da sexualidade em “A Arqueologia do Saber”, na seção reservada ao que denominou de outras arqueologias.

Voltamos, novamente, ao ponto de partida arqueológico (talvez, jamais tenhamos dele saído) para nos depararmos com o campo da sexualidade. Posteriormente concebido como dispositivo ${ }^{8}$, momento em que nos será apresentada a noção de biopoder, na "Arqueologia", o campo da sexualidade é descrito sob a perspectiva de suas regras de formação enunciativa. Eis o que propõe o filósofo?: "Consideremos, por exemplo, uma descrição arqueológica da 'sexualidade' [...], perguntaríamos se [...] a sexualidade, fora de qualquer orientação para um discurso científico, não é um conjunto de objetos de que se pode falar (ou de que é proibido falar), um campo de enunciações possíveis (quer se trate de expressões líricas ou de prescrições jurídicas), um conjunto de conceitos

\footnotetext{
${ }^{6}$ FOUCAULT, Michel. A ordem do discurso. Aula inaugural no Collège de France, pronunciada em 2 de dezembro de 1970.13 ed., São Paulo: Edições Loyola, 2006.

${ }^{7}$ FOUCAULT, Michel. A arqueologia do saber. Tradução de Luiz Felipe Baeta Neves. Petrópolis: Vozes; Lisboa: Centro do Livro Brasileiro, 1972, p. 177, p. 177.

${ }^{8}$ FOUCAULT, Michel. História da sexualidade I: A vontade de saber. Trad. Maria Thereza da Costa Albuquerque e J. A. Guilhon Albuquerque. Rio de Janeiro: Edições Graal, 1988.

${ }^{9}$ FOUCAULT, Michel. A arqueologia do saber. Tradução de Luiz Felipe Baeta Neves. Petrópolis: Vozes; Lisboa: Centro do Livro Brasileiro, 1972, p. 216.
} 
(que podem, sem dúvida, ser apresentados sob a forma elementar de noções ou de temas), um jogo de escolhas (que pode aparecer na coerência das condutas ou em sistemas de prescrição)”.

O que lemos, na sequência desse esboço de descrição arqueológica da sexualidade, é o vínculo estreito entre um saber sobre o sexo e as relações de poder (embora essa expressão não esteja presente no texto), na medida em que tal análise pressupõe que proibições, exclusões, limites, valorizações, liberdades e transgressões da sexualidade, sejam verbais ou não, estejam ligadas uma prática discursiva determinada. Desse entrecruzamento, sabemos, é produzida a verdade sobre o sexo do sujeito.

A respeito da verdade, Veyne afirma que ela figura entre os componentes do próprio dispositivo, uma vez que cada sociedade possui seu regime geral de verdades. Em vista disso, o dispositivo é algo que engloba “coisas e idéias (entre as quais a verdade), representações, doutrinas, e até mesmo filosofias, com instituições, práticas sociais, econômicas, etc" ${ }^{\text {"10 }}$. Conforme assinala esse autor, os dispositivos têm por limite, na sua finitude, as fronteiras históricas de um discurso.

Esperamos ter conseguido alinhavar as discussões, aqui reunidas, em torno de seis termos conceituais que conferem certa regularidade à dispersão dos temas que foram objeto de discussão em cada um dos artigos: enunciado, monumento, prática, poder, verdade e sujeito. Vejamos, brevemente, como os artigos mobilizam os conceitos e as noções do método arqueogenealógico.

“A Arqueogenealogia Foucaultiana como lente para a análise do Governo da Língua Portuguesa no Brasil: continuidades e disrupções”, de Ivânia dos Santos Neves e Maria do Rosário Gregolin, abre o dossiê com ênfase dada às estratégias de governamentalidade que institucionalizaram a língua portuguesa como um saberpoder que se instala ao longo da história colonial do Brasil. As autoras concentram-se em dois prolongamentos descontínuos desse acontecimento, a saber, o momento inicial da colonização ocorrido no Brasil, com o ensino jesuítico, ao século XVIII e a promulgação do Diretório dos Índios; e o período Imperial até a instalação da República (ao longo do século XIX e início do XX). Observam que “A língua [...] envolve o corpo e suas formas de vida num espaço biopolítico de disputa de poder. Ao mostrar como o corpo foi investido de poder no decorrer da história brasileira”. Neves e Gregolin buscam verticalizar a história tácita das políticas linguísticas no Brasil para além de leis ou decretos, compreendendo-a com suas normalizações insuspeitas, em seus cotidianos espaços de poder.

O acontecimento da colonização passa, também, por um processo de monumentalização, realizado pela pesquisa de Flávia Marinho Lisbôa, em seu texto "O dispositivo colonial: entre a arqueogenealogia de Michel Foucault e os estudos decoloniais”. Nele, Lisbôa visa estabelecer relações teórico-conceituais entre o discurso, a arqueogenealogia foucaultiana e a colonialidade, com vistas à compreensão de como os estudos discursivos assentados nas/pelas lutas sociais podem ser potencializados pela noção de "genealogia" com a insurgência dos saberes subalternos. Partindo, assim, desse aporte teórico e metodológico, a autora direciona suas reflexões para defender o que podemos chamar de exercício de um poder advindo daquilo que Lisbôa chama de "Dispositivo Colonial".

${ }^{10}$ VEYNE, Paul. Foucault: seu pensamento, sua pessoa. Rio de Janeiro: Civilização Brasileira, 2011, p. 57. 
"Seduzir as massas: líderes populares e partidos políticos como dispositivos de controle das multidões", de Amanda Braga, é outro importante trabalho que lança luz sobre o funcionamento dos dispositivos. Para tanto, a autora nos convida a refletir sobre a atuação dos líderes populares e dos partidos políticos como dispositivos de controle das multidões, que operam abertura e fechamento das massas ao sabor das paixões políticas. Balizada por um construto teórico do qual participam Foucault, Le Bon e Courtine, Braga problematiza o que chama de "emergência da multidão como acontecimento histórico e objeto de pensamento no século XIX, bem como sua natureza e seus dispositivos de controle”. As duas fotografias de Lula, aclamado pela multidão, servem de mote para se demonstrar o funcionamento dos dispositivos que nelas estão materializados.

A noção de discurso como prática, em articulação com a ideia de que a web é um espaço heterotópico, mobiliza as análises feitas por Claudemir Sousa, em "Práticas discursivas afro-brasileiras: a irrupção de saberes dominados nas mídias". No artigo, Sousa reflete sobre a proliferação de saberes e de práticas afrodescendentes nos sites "Portal Geledés" e "Mundo Negro". Suas análises mostram que, em virtude de os sujeitos afrodescendentes nem sempre poderem enunciar e serem vistos na grande mídia, "elaboram formas de resistência nas mídias alternativas e sociais digitais, mobilizando uma linguagem que rompe os padrões de normatização linguística calcados no português europeu", tencionando os efeitos do dispositivo colonial que se sobrepõe a essa subjetividade.

Da posição de sujeito afrodescendente, somos conduzidos às formas pelas quais se constitui outra posição de subjetividade: a sujeita mulher indígena na web, por meio de suas práticas de resistência. Esse é o foco da discussão realizada por Raimundo de Araújo Tocantins, no texto "Mulheres indígenas na web e as escritas de si como práticas de resistência", cujo corpus discursivo é formado por dois enunciados construídos nas redes sociais por duas mulheres de diferentes etnias: Daiara Tukano e Célia Xakriabá. O autor objetiva compreender em que medida se manifesta, discursivamente, a "elaboração do protagonismo de mulheres indígenas presente na web, compreendido aqui como as narrativas de si nos espaços da internet”. Tocantins traça um percurso teórico e de análise que contempla antigos e novos regimes de visualidades, o funcionamento da memória das imagens empreendidas em relação aos indígenas, as convergências culturais e outros lugares de enunciação em que tais sujeitos protagonizam as escritas de si como práticas de resistência.

Discurso, enunciado, sujeito, poder, saber e biopolítica, este é o aparato teórico do qual se vale Francisco Vieira da Silva, no artigo intitulado ““"Depois a louca sou eu”: estratégias biopolíticas e produção de subjetividade em discursos sobre relacionamento abusivo", para discutir "as condições de possibilidade que fazem irromper discursos acerca do relacionamento abusivo na contemporaneidade, através do exame do funcionamento de estratégias biopolítica na produção de tais discursos e de como o sujeito que enuncia acerca do relacionamento abusivo se constitui numa relação consigo mesmo e com o outro". Para Vieira, os enunciados sobre as relações abusivas dão visibilidade ao trabalho que elas efetuam sobre si e sobre o outro, o que coloca em jogo determinadas estratégias bipolíticas em torno da saúde e do bem-estar da mulher no âmbito dos relacionamentos amorosos.

Num incessante movimento de ir e vir da arqueologia para a genealogia, como tentamos sinalizar na primeira parte deste Editorial, observamos que os autores e as autoras dos artigos propõem formas de se pensar, em termos discursivo, as relações existentes e conflituosas entre saber, poder e subjetividade. Isso está posto nos 
artigos cujas sínteses foram feitas até aqui, bem como se manifesta nas demais reflexões. Assim, um retorno à fase arqueológica de produção dos saberes volta a direcionar o olhar aos aspectos enunciativos e as suas regras de formação.

Roselene de Fatima Coito, em "Uma nova volta à "nova volta da espiral”: movimentos do signo", traça uma significativa discussão acerca da relação entre o signo e a teoria do enunciados, com base nas obras "A Arqueologia do Saber" e "As palavras e as Coisas”, de Michel Foucault. A autora busca respaldo, também, na leitura que Deleuze faz do enunciado para, então, "discutir o enunciado, o signo e a linguagem como constitutivos de uma ordem que estabelece paradigmas do que se toma como ciência e como arte, sem, no entanto, desconsiderar que, seja num paradigma ou noutro, há o foco do poder".

"Cartografias discursivas: O campo associado e o objeto na constituição do dispositivo", assinado por Bruno Franceschini e Cleudemar Alves Fernandes, investiga a produção de subjetividade do aluno hiperativo produzida na/pela linguagem, com vista a problematizar os efeitos de verdade dos discursos sobre esse sujeito da educação. O conceito de dispositivo dá o norte às análises empreendidas, a partir das quais os dois autores interrogam as instituições escolar e médica como produtoras de discursos sobre "quem é esse sujeito da educação, objeto de saberes e poderes que o caracterizam, respectivamente, como um sujeito indisciplinado e doente, que necessita de tratamento especializado, à margem da norma".

No artigo "As relações entre animais e humanos: uma breve arqueologia de discursos", Carlos Piovezani e Manoel Sebastião Alves Filho apresentam suas considerações sobre a noção de discurso, de descrição arqueológica e dos postulados foucaultianos acerca da "crítica do documento", "do arquivo" e das "unidades discursivas". As discussões apresentadas por Piovezani e Alves Filho são movidas pela tarefa de "expor a fundamentação teórica e metodológica a partir da qual identificamos e descrevemos uma profunda descontinuidade de discursos sobre as relações entre animais e humanos, que pode ser assim resumida: existência da linguagem entre eles, em uma posição, e embrutecimento dos bichos e destituição de sua linguagem, na outra". Os enunciados que assim objetivam a relação sinalizada no título do artigo emergem de um conjunto de textos mitológicos e ritualísticos de sociedades ditas primordiais.

Vanice Maria Oliveira Sargentini e Joice Camila Corsi, em "O enunciado à primeira vista: as (im)possibilidades de uma leitura da superfície dos discursos", expõem a produtividade de conceitos elaborados na fase arqueológica para a análise de discursos, em especial, problematizam o conceito de enunciado, considerando-se o fato de que este possa ser compreendido de formas distintas, haja vista suas leis de raridade, de acúmulo e de exterioridade. Isso é feito com base em um amplo arquivo composto por discursos políticos pronunciados por presidentes a respeito dos migrantes e sobre a política migratória. Como informam as autoras, "Pretendemos com a análise apontar que o conceito de enunciado no plano do discurso articula-se à análise linguística, mas neste entrecruzamento legitima a produção de alguns sentidos e não de outros”.

A subjetividade negra em confronto com o dispositivo religioso cristão é o tema das análises que encontramos em "A objetivação de sujeitos negros amazônicos e de práticas de Marabaixo", texto no qual Ednaldo Tartaglia e Pedro Navarro empenham-se em dar visibilidade às práticas discursivas que produzem saberes acerca dos sujeitos negros amazônicos, especialmente, aqueles praticantes do Ciclo do Marabaixo 
macapense. O movimento descritivo-analítico sinaliza que a Igreja construiu um saber deslegitimador a respeito dos negros e de suas práticas de Marabaixo, o qual se inscreveu na historicidade desses sujeitos e do corpo social do estado do Amapá.

A coletânea é finalizada com a resenha do Livro "Audiovisualidades: elaborar com Foucault", de autoria de Nilton Milanez. Vívian de Nazareth Santos Carvalho, que assina a resenha, retoma duas importantes indagações desta obra, uma que recai sobre as regras de formação para os discursos das audiovisualidades, e outra que se volta para saber quais seriam os objetos que se levantam em direção à constituição de um filme. Carvalho informar que "Audiovisualidades" assenta-se sobre os postulados teórico-metodológicos presentes em "A Arqueologia do Saber" com o intuito de "compreender aquilo que somos, como nos organizamos e o que nos torna sujeitos no presente".

Com este segundo volume dos "50 anos de "A Arqueologia do Saber": as contribuições aos estudos da linguagem no Brasil”, esperamos ter cumprido a missão de disponibilizar à comunidade científica um conjunto exemplar de trabalhos os mais atuais e representativos de uma maneira de se fazer análise de discursos, que nos identifica e nos dá o sentimento de pertença a um grupo de pesquisadores e de pesquisadoras comprometidos com a imperiosa tarefa de dar a conhecer as "formas de poder ali onde ele é, ao mesmo tempo, o objeto e o instrumento disso: na ordem do 'saber', da 'verdade', da 'consciência', do 'discurso' 11.

\footnotetext{
${ }^{11}$ FOUCAULT, Michel. Os intelectuais e o poder. In: FOUCAULT, Michel. Estratégia, poder-saber. Ditos \& Escritos IV. Organização e seleção de textos por Manoel Barros da Mota, tradução de Vera Lúcia Avellar Ribeiro, 2. Ed.; Rio de Janeiro: Forense, 2006 , p. $37-$ 47.
} 